\title{
Nuclear Medicine in the Imaging and Management of Breast Cancer
}

\author{
Luciano Izzo ${ }^{1}$, Sara Savelli ${ }^{1}$, Andrea Stagnitti ${ }^{2}$ and Mario Marini ${ }^{2}$ \\ Sapienza University of Rome, Umberto I hospital \\ "Department of Surgery "P. Valdoni" \\ ${ }^{2}$ Department of Radiology \\ Italy
}

\section{Introduction}

Axillary nodal status is the most important prognostic factor for patients with breast cancer. Clinical assessment and imaging modalities are not always reliable.

Surgical removal and histopathological examination of axillary lymph nodes remain essential methods of staging the axilla and planning breast cancer therapy (Chu et al, 2010; Perry, 2001) But whether axillary lymph node dissection improves survival remains controversial. Historically, nodal involvement was determined by conventional axillary dissection. (Gill, 2009)

Till 1990s conventional axillary dissection was performed in all women with breast cancer with great incidence of morbidities such as pain, numbness, shoulder joint stiffness, scarring, infection and long term lymphoedema. (Mansel et al, 2006)

Sentinel lymph node biopsy has recently been introduced in the treatment of women with breast cancer.

The American Society of Clinical Oncology in 2005 (Lyman, 2005), and more recently the British Association of Surgical Oncology (Association of Breast Surgery, 2009) endorsed sentinel lymph node biopsy (SLNB) as the recommended method of staging early breast cancer in clinically node negative patients.

The sentinel lymph node hypothesis is that the sentinel lymph nodes are the first nodes draining a tumor and that focused histological analysis of sentinel lymph nodes is predictive of the status of the regional nodes thus accurately staging the breast disease with lower incidence of complications. (Krag et al, 1998; Morton et al, 1992)

Giuliano et al (Giuliano et al, 1994) demonstrated that the status of sentinel nodes, with respect to the presence of metastases, accurately reflected the metastatic content of the local nodal basin.

Early works support the feasibility and accuracy of sentinel lymph node biopsy.

However, the optimal management of the axilla remains uncertain as axillary lymph node dissection, sentinel lymph node biopsy and lymphoscintigraphy have been described as reliable alternative procedures.

By combining preoperative lymphatic mapping with intraoperative gamma probe detection nuclear medicine procedures are increasingly used to identify and detect the sentinel node in breast cancer, and in other malignancies. 
Some surgeons have begun to offer sentinel lymph node biopsy as an alternative to axillary dissection for women with small infiltrating breast cancer; axillary dissection is performed only if tumor is found in the sentinel lymph node.

Moreover in the recent years percutaneous imaging guided localization has been increasingly used to diagnose carcinoma previously detected at screening mammography. In this setting sentinel lymph node biopsy is considered the gold standard for axillary staging according to the low rate of node metastasis in nonpalpable infiltrating breast cancer.

\section{Sentinel lymph node biopsy}

In contrast to the procedure of lymphoscintigraphy for melanoma, in breast cancer there has not yet been reached a consensus for many topics regarding sentinel lymph node biopsy methodology such as tracer characteristics, injection volume, and principally the site of administration.

\subsection{Tracer characteristics}

Sentinel lymph node biopsy is commonly performed using radioisotopes and/or blue dye that facilitate sentinel lymph node mapping. (Jakub et al, 2010)

However, it is still undefined which reagent is more suitable for lymphoscintigraphy. Several data from literature suggest that radioisotopes based on technetium-99m colloid are superior to blue dye in detecting SLN in breast cancer. (Somasundaram et al, 2007)

Historically, the colorimetric detection of lymph nodes by the trypan blue (or equivalent) preceded the use of radioisotopes. For its rapid migration kinetics, the dye is injected in 1-4 $\mathrm{ml}$ intra-operatively either into or around the tumour, or superficially into the section of areolar tissue that correlates with the index quadrant, 5 to 10 minutes before surgery. Patent blue dyes bind to interstitial albumin and are taken up by local lymphatic tissue. The efficiency with which the lymphatics are converted to bright blue channels by the vital dyes reflects their small hydrodynamic diameter, their ability to disperse quickly and even their capacity to readily progress through and beyond the nodes. The dissection is guided by the path of the blue lymphatic channels that lead to one or more nodes, more or less intensely colored. The choice of vital dye varies between operating surgeons. In the United States, Isosulfan blue, as a $1 \%$ sterile solution is the vital dye approved for use in humans by the Food and Drug Administration. Isosulfan blue is a monosodium isomer of the 2,5 disulfonated triphenylmethanes which are also known as the patent blue dyes (Leong et al, 2000). One of these patent blue dyes, Patent Blue Violet (or Patent Blue V), is preferentially used in Australia and Europe. Another vital dye, Indocyanine green has been used in Japan. All the vital dyes are selectively absorbed into lymphatic tissue and therefore facilitate localisation of the lymphatic channels and nodes. (White et al, 2011)

After the introduction of the isotope method, some teams have remained faithful to the colorimetric method while others are converted to the exclusive use of the radiocolloides; but the majority of teams use the combination of the two techniques (Tafra et al, 2002), the results are usually best with only one, like a radiocolloide. The advantage of vital dyes is their "real time" efficiency in guiding the gamma probe to the sentinel node. This reduces exploratory dissection and tissue plane disruption and leads to a surgical exploration much less aggressive than with isotope technique, which has the advantage of transparency of the tissues to the gamma photons. Moreover the injection of blue presents a number of 
disadvantages, the most serious is the risk of allergic shock, whose incidence is approximately $1 \%$; review of the data suggests otherwise that the risk of severe anaphylaxis (grade 3) can be as low as $0.06 \%$, and up to $0.4 \%$ for patients undergoing SLNB when data is analysed from large trials or databases. (Barthelmes et al, 2010; Hunting et al, 2010) Methylene blue has been used as an alternative to the other vital dyes. Its attraction as a mapping agent is its low risk profile. The risk of anaphylaxis from patent blue dyes may also be reduced by pre-operative prophylaxis with corticosteroids, antihistamines and H2receptor antagonists.

In a study published recently Derossis and al. (Derossis et al, 2001) show that the rate of identification of the sentinel node by dye ganglion has remained stable over time $(89 \%$ in the first 500 patients and $90 \%$ in the last 500 patients) while it has increased with the isotopic technique (respectively from $88 \%$ to $98 \%)(p<0.0015)$. Moreover blue dyes also contribute to increased sensitivity of the SLNB procedure when used in conjunction with radioactive nanocolloids.

Sentinel node biopsy (SNB) by radioisotopes is a widely accepted and reliable surgical method for staging breast cancer in patients with unknown positive axillary lymph nodes involvement.

The reproducibility of lymphoscintigraphy for sentinel node detection varies from $85 \%$ to $88 \%$ and the method appears to have a high interobserver agreement.

Injection of the radio-isotope occurs between 2 and $24 \mathrm{~h}$ before surgery. Radioactive nanocolloid is injected preoperatively, with the assistance of radiological imaging either around the tumour, or into the overlying skin. It is thought that nanocolloids become entrapped within the sentinel lymph nodes either through a function of their particulate size (the larger hydrodynamic diameter of 50-100 nm for nanocolloid requires a transit time of usually more than $1 \mathrm{~h}$ and $15 \mathrm{~min}$ ) or because of phagocytosis by leukocytes which migrate to and are retained within the draining lymph nodes. These entrapment processes are unlikely to be mutually exclusive, and other mechanisms may also exist, but the end result is localisation of the nanocolloid within the sentinel nodes rather than its diffuse spread to secondary nodes (Cody et al, 2001).

\subsection{Site of administration}

The exact site of injection of the mapping agent varies between studies, but can be broadly divided into "superficial" or "deep". (Nieweg et al, 2004; Celliers et al, 2003)

Lymphoscintigraphy by subdermal tracer administration is able to detect axillary lymph nodes in $98 \%$ of the cases but the method is accompanied by a low visualization incidence of drainage outside the lower axilla such as the internal mammary chain. This latter aspect appears to occur in $16 \%$ to $35 \%$ in the series using peri- or intratumoural administration with an axillary rate of visualization of $75 \%$ to $98 \%$. Although peritumoural administration is predominantly associated with late lymph node detection, the early appearance observed after subdermal and intratumoural tracer injection justifies the obtention of early gamma camera images (McMasters et al, 2001; Boolbol et al, 2001). Intradermal injection delivers macromolecules to loco-regional lymph nodes faster than subcutaneous injection, suggesting easier lymphatic vessel access. Although the majority of patients has different pathways of lymphatic drainage from the ipsilateral breast and upper limb, in a small minority of patients the drainage pathway is through a common SLN. Such patients may be at increased risk of developing upper limb breast cancer-related lymphoedema after SLN biopsy (Cody et al, 1999). 
The best injection site remains a hotly debated topic. The options are injected intratumor, peritumoral, subareolar, periareolar, subcutaneous and intradermal. The number of injection sites is variable, ranging between one and six.

Most authors agree intratumoral site. Other methods of injection have all excellent results, without any real objective comparisons have been made, but now the simplest and most favorable for the intraoperative detection, is the intradermal periareolar apprauch.

\subsection{Injection volume}

The choice of an intradermal injection allows only a small volume $(0.2 \mathrm{~mL})$ per injection. When the intradermal injection is not possible there is a disagreement between American and European teams.

The first team is for a large volume (up to $6 \mathrm{~mL}$ ) to dilate the lymphatic channels and force the passage of the suspension of radiocolloid to the sentinel node. In contrast, the European teams, particularly under the impetus of the European Institute of Oncology in Milan, defend the injection of a small volume ( 0.1 to $0.4 \mathrm{~mL}$ ) according to best physiological conditions.

The debate is difficult because the reported results are excellent in both cases.

Moreover, some prominent American teams also began to advocate a volume of $0.1 \mathrm{~mL}$.

\subsection{Histopathological analysis}

The histopathological analytical methods for excised sentinel lymph nodes have been improved in order to increase staging accuracy and reduce false-negative rates.

The dissected tissue containing the sentinel lymph node is placed in $4 \%$ formalin solution. Frozen slide analysis is not performed. The sentinel lymph nodes are separated from surrounding adipose tissue, bisected, lamellated and embedded. Subsequent serial sections are made.

The relevant sentinel lymph node pathology must include multisection staining with hematoxylin and eosin.

Immunohistochemical analysis with antibodies to cytokeratin is also commonly used for hematoxylin and eosin-negative cases and may facilitate the detection of small deposits, thereby enhancing the screening of sentinel lymph nodes sections.

The majority of sentinel lymph node cases can be classified as positive or negative based on the presence or absence of macrometastasis. The 2003 edition of the TNM classification uses $2.0 \mathrm{~mm}$ as the cutoff size that distinguishes between micro- and macrometastasis.

The cutoff value for isolated tumor cells or so-called submicrometastasis is $0.2 \mathrm{~mm}$.

The significance and practical relevance of micrometastases, isolated tumor cells and the value of immunohistochemical analysis also require further definition.

\subsection{Axillary excision complications}

Lymphedema is one of the most feared complication of breast cancer surgery.

Sentinel lymph node biopsy has markedly reduced its incidence but has not eliminated it. The incidence of measured lymphedema after sentinel lymph node biopsy has been reported to be 0 to $22 \%$; most studies report an incidence of 3 to $7 \%$.

The prevalence of subjectively reported lymphedema ranges from 0 to $15 \%$. (Veronesi et al, 2003; Leidenius et al, 2005; Langer et al, 2007; McLaughlin et al, 2008; Armer J et al, 2004; Lucci A et al, 2007; Crane-Okada et al, 2008; Helyer LK et al, 2009; Schrenk et al, 2000; Kwan et al, 2010 ) 
The variation in incidence rates is influenced by the length of follow-up after the axillary surgery, by the absence of a standard definition of both measured and perceived lymphedema, and by the lack of agreement between patient perceptions and objective measures.

Many authors have shown that in women treated for breast cancer, there is a large variation in the prevalence of lymphedema depending on the definition used. In their population of 211 women treated for breast cancer, they found the incidence of lymphedema at 30 months post-treatment varied widely depending on the measure and definition used: $91 \%$ using the definition of a 2-cm difference in arm circumference, $67 \%$ using the definition of a $200-\mathrm{ml}$ increase in volume by perometry, $45 \%$ using the definition of a $10 \%$ increase in volume by perometry, 41\% using self-report of limb heaviness or swelling (Armer et al 2009).

Dayes et al (Dayes et al, 2006, 2008) found that more than $20 \%$ of women presenting (presumably with the perception of arm swelling) to lymphedema clinics at large regional cancer centers had no measurable lymphedema ( $5 \%$ excess arm volume compared with the contralateral arm). Similarly, Querci della Rovere et al (Querci della Rovere et al, 2003) reported on a series of 199 patients, 10\% (20 of 199) of whom perceived current arm swelling. Half of these patients with perceived swelling were not found to have objectively measured lymphedema by circumferential measurements.

Women who had surgery on their nondominant axilla less frequently reported perceived arm swelling in the absence of measured arm swelling, and less frequently perceived arm swelling even when there was objectively measured lymphedema. This suggests that patient perceptions of lymphedema are less influenced by sensory changes in the nondominant arm compared with the dominant arm.

It is possible that patient perceptions of lymphedema are influenced by patient knowledge of the number of nodes that was removed at the time of the sentinel lymph node biopsy.

\subsection{Limitations}

Several factors affect the technical success of sentinel lymph node. First of all the success rate is higher with experience.

The reported technical success rates for sentinel lymph node biopsy are $69 \%-99 \%$ for radioisotope alone, $67 \%-93 \%$ for blue dye alone and $90 \%-100 \%$ for the combined use. Radioisotopes injection allows the surgeon to identify the sentinel nodes prior to making any incision, blue dye allows the surgeon to visually identify the sentinel nodes; the combined method may shorten the learning curve and increase the likelihood of technical success.

The main limitation of this method is due to the appearance of false negatives that may be caused by tumor lymph node blockage of the sentinel lymph node and uptake in the neighboring lymph nodes. Infiltered sentinel nodes are generally increased in size and firm. Thus, they can be detected by intraoperative palpation, even when there is no uptake by the radiotracer. Intraoperative axillary palpation, once the sentinel lymph node is done, reduces the false negative rate.

Moreover identification of sentinel lymph node is dependent on uptake of the labeling agent by the lymphatic pathway that drain the tumor. Previous surgery or surgical biopsy may disrupt this lymphatic pathway thus lowering the success rate and the accuracy of sentinel lymph node biopsy. Krag et al (Krag et al, 1998) reported a significantly higher frequency of failure to identify a hot spot in women who had undergone prior surgical biopsy when compared to women that have undergone percutaneous breast biopsy or no surgical biopsy at all. Other authors did not find a significant difference between the groups. 
A reduced identification rate in older patients is consistently reported. The increased fatty tissue in the breast in elderly patients might cause a decreased lymphatic flow. It is also suggested that the replacement of lymph nodes by fatty tissue decreases the capacity of lymph nodes to retain the radioactive colloid.

Tumor size is also associated with the detection rate, showing a low identification rate in tumors $>5 \mathrm{~cm}$ in size. Patients with large tumors have in fact a greater risk of extensive axillary tumor burden, which decreases the lymphoscintigraphic visualization.

\section{Radioguided occult lesion localization}

With increasing awareness of early breast cancer detection among the population, the use of mammography and breast ultrasound in screening has gained prominence in recent years. As a result, small non-palpable occult breast lesions are detected with increasing frequency. These lesions are initially characterised by percutaneous biopsy. If these turn out to be malignant, in terms of being invasive or in situ, or heterogeneous (such as atypical ductal hyperplasia, radial scar, papillary lesions, or those with imaging-pathologic discordance), diagnostic or therapeutic surgical excision becomes warranted.

It is then necessary to accurately localize such occult breast lesions, with the aim to excise the smallest amount of breast tissue and yet remove the entire lesion whilst achieving adequate clear margins.

A variety of preoperative localisation techniques for nonpalpable breast lesions has been described in the literature: hypodermic needles, wires (the most widely accepted technique), carbon solution, methylene blue dye. For the past 10 years, the radioguided occult lesion localisation (ROLL) technique has also been proposed either by means of radiotracer injection or by intratumoral deposits of radioactive seeds, and its role has been increasing in recent years.

\subsection{Hookwire localization}

For years, hookwire localization has been the traditional localization procedure in patients undergoing lumpectomy or wide local excision of clinically occult breast lesions (Chen et al, 2005).

This technique has several well described disadvantages such as incidental migration, kinking or fracture of the wire, and difficult logistics between the radiology, surgical and nuclear medicine departments.

Moreover hookwire localization has a number of other drawbacks.

Negotiating the wire through a very dense breast can be technically difficult for radiologists. The hookwire may be imprecisely placed or even displaced in fatty breasts, which is of particular concern when a patient has to move from one centre to another for surgery. The pathologist may find the wire difficult to dissect, with possible subsequent damage to the specimen.

\subsection{ROLL radioguided occult lesion localization}

Radioguided occult lesion localization is a new technique which allows identification of non palpable breast lesion in breast cancer using, on the model of sentinel node procedure, injection of a radiotracer over the tumour lesion. With a gamma detection probe, it is then possible during surgery to identify the lesion. (Belloni et al, 2011) 
Radioguided occult lesion localization was pioneered in 1996 at the European Institute of Oncology, Milan. Inspired by the rationale for sentinel node biopsy, radioguided occult lesion localization involved the inoculation of macroaggregates of human serum albumin labelled with radioactive technetium $99(99 \mathrm{mTc})$ directly into the site of a nonpalpable breast lesion, with mammography or ultrasound guidance. After radiotracer injection, a gammadetecting probe was used to locate the lesion during surgery, allowing the surgeon to evaluate its skin projection and decide the best approach with an acceptable cosmetic outcome (Luini et al, 1998).

After the first publications on ROLL it was proposed that human serum albumin should be used as a radiotracer, with large particles ranging from 10 to $150 \mu \mathrm{m}$ in diameter. For radioguided localisation of non-palpable breast lesions it is preferable that radiotracers do not migrate rapidly by lymphatic channels, in order to allow lesion identification by the surgeon using the probe. For this reason, it is recommended that larger 99mTc-labelled colloid particles of albumin should be used than are employed for sentinel lymph node identification, for which small particles from 200 to 1,000 nm are preferred. Other small particles, such as sulphur colloid, which are used in most services in the United States, flow quickly to the axillary lymph nodes and are often trapped in several nodes.

99mTc-labelled dextran was first used in lymphoscintigraphy by Henze et al in 1982 (Henze et al, 1982) that demonstrated its usefulness in SLN mapping in breast carcinoma, achieving successful identification of the SLN in $98 \%$ of cases. The sensitivity of SLN biopsy in predicting axillary node status was $100 \%$, with no false-negative results. Another argument in favour of dextran is its low cost: it is much less expensive than human albumin.

Radiation safety to patient and staff in radioguided occult lesion localisation procedures has been secured and radioguided occult lesion localization is considered a reliable and safe alternative to wire localization.

Technetium-99m has a short half-life of 6 hours and low-dose gamma radiation is used. Cremonesi et al (Cremonesi et al, 1999) calculated the effective dose for patient, which is $9.25 \mu \mathrm{Sv}$, less than half the dose of a chest X-ray $(0.02 \mathrm{mSv})$.

Radiation due to additional mammograms needed for hookwire localization (1-2 mSv) may exceed that involved for 100 to 200 radioguided occult lesion localisation procedures.

Finger doses to breast surgeons and radiologists are also minimal, as stated by Rampaul et al (Rampaul et al, 2003) and amount to $9.3 \pm 3.3 \mathrm{mSv}$ and $0.5 \pm 0.1 \mathrm{mSv}$, respectively.

The advantages of this technique can be summarised as: precise localisation and accurate surgical removal; reduction of tissue damage in the final pathological specimen (as the wire is not present in the specimen); accurate frozen section (if indicated); improved rate of clear margins; reduced size of the excised specimen; increased patient comfort; decreased operative time; and reduced number of reoperations (cost effectiveness).

One of the important drawbacks of such a technique is radiotracer spillage within the mammary gland that makes the precise lesion resection difficult, and this requires the use of a hook-wire collocation to reach the lesion. The possibility of obtaining an intraoperative image of the specimen could help to confirm whether the lesion is correctly removed. Some types of portable gamma cameras have been designed, but up to now, intraoperative use has been confined to surgery of parathyroid adenomas and sentinel lymph node location.

The intraoperative acquisition of such images can predict the involvement of surgical margins, avoiding future surgical procedures.

Reported advantages of radioguided occult lesion localization are (van der Ploeg et al, 2008): precise localisation and accurate surgical removal, reduction in the tissue damage within the 
final pathological specimen, accurate frozen section (in the case a differential diagnosis is required between DCIS and invasive cancer), improved rate of clear margins avoiding the emotional trauma of another operation, reduced size of the excised specimen, better concentricity of the lesion, increased patient comfort, decreased operative time, and reduced rate in re-do surgery reducing costs. Moreover no control mammogram is needed after localisation, allowing reduction in both costs and radiation dose.

When comparing the radioguided occult lesion localization technique with the hookwire localization in the radioguided occult lesion localization group between $69 \%$ and $84 \%$ of the lesions were radically excised, compared with $44-60 \%$ of the lesions in the hookwire localization group.

The studies that combined radioguided occult lesion localization and the sentinel node procedure mentioned even higher percentages of radically excised specimens ranging from $90 \%$ to $95 \%$ and an identification rate of sentinel nodes up to $100 \%$, resulting in minimisation of the surgical intervention and a decrease in postoperative morbidity.

One randomised controlled trial mentioned that the radioguided occult lesion localization procedure had a faster localisation time, was easier to perform, was less painful and gave a better cosmetic result than hookwire localization.

Many studies have reported good margin clearance with radioguided occult lesion localization, which ranged from 75 to $100 \%$. In a recent publication, the free margin clearance rate was $84 \%$ after radioguided occult lesion localization compared with $60 \%$ after hookwire localization.

An important advantage of the ROLL technique is that it takes advantage of the radioactive tracer that is used anyway to detect the sentinel node. Therefore, it is not necessary to use a separate injection for the SN detection as was used in some studies. Feggi et al (Feggi et al, 2001) demonstrated successfully, that it is possible to perform ROLL and sentinel lymph node mapping with a single injection of Technetium-labelled Nanocolloid.

Ductal migration of isotope is an uncommon problem with radioguided occult lesion localization.

Another constraint is the timing of surgery, which has to be performed within 4 hours of radioactive occult breast lesion localization completion, lest the tracer count is not high enough to enable accurate gamma probe-guided excision.

\subsection{SNOLL sentinel node and occult lesion localisation}

Sentinel node localization can be performed together with radioguided occult lesion localization. (Strnad et al, 2006)

How to execute lymphoscintigraphy in patients with non-palpable lesions scheduled to undergo radioguided surgery for the primary lesion is still the subject of debate; it is not clear whether it is better to employ a single tracer and single injection method, as recently proposed, or a dual tracer method with injection at different sites. (Patel et al, 2004)

Filtered Tc-99m labelled sulphur colloid with a particle size of smaller than 100 nanometers is injected. Tracers flow via the lymphatics and accumulate in the sentinel nodes. Subsequent scintigraphy can be performed as usual. The application of a radioisotope in sentinel node and occult lesion localization has revolutionized the original two-step procedure into one with very promising results.

Otherwise some authors report that a dual administration of radiopharmaceuticals, i.e. the radioguided occult lesion localization procedure with intralesional injection of macroaggregates of $99 \mathrm{mTc}$-labelled human serum albumin followed by lymphoscintigraphy 
with subdermal injection of nanocolloids, represents the best approach to localise both nonpalpable lesions of the breast and axillary sentinel nodes on the same day.

Also the Italian group of the European Institute of Oncology (De Cicco et al, 2004, 2002) confirmed in a recent paper that the combination of the ROLL procedure with direct injection of human serum albumin into the lesion and lymphoscintigraphy performed with subdermal injection of radiocolloids represents the method of choice for accurate localisation of both non-palpable lesions and sentinel nodes.

\subsection{RSD radioactive seed localization}

There are a few reports describing alternative techniques to localise non-palpable breast lesions. In 2001, Gray et al (Gray et al, 2001) reported on a refinement of the technique of radioguided surgery. In this technique, known as "radioactive seed localization" (RSL), a radio-opaque titanium seed containing Iodine- 125 is inserted into the tumor under stereotactic or ultrasound guidance, and the gamma probe is again used to guide surgical resection.

Use of radioactive seed localization such as an iodine-125-radiolabelled (I-125) seed for localization of non-palpable breast tumours could potentially prevent the problems related to hookwire localization and seems a promising approach for the resection of nonpalpable breast lesions. (Barros et al, 2002)

Radioactive seed localization is at least equivalent compared with wire localization in terms of the ease of the procedure, removing the target lesion, the volume of breast tissue excised, obtaining negative margins, avoiding a second operative intervention, and allowing for simultaneous axillary staging.

Radioactive seed localization is safe, effective, and compared to wire localization, reduces the rates of intraoperative re-excision and reoperation for positive margins by $68 \%$. Patient satisfaction is improved with radioactive seed localization.

RSL has been reviewed by Jakub et al (Jakub et al, 2010). Subsequent randomized and nonrandomized trials have shown improvements in positive margin rates compared to standard hookwire guided localization. In studies of both radioguided occult lesion localization and radioguided seed localization, there was rapid adoption by surgeons and radiologists, and satisfaction and acceptance by patients.

\subsection{Probes}

Currently, tumoral harvesting is aided by using a hand-held gamma probe. This device locates the highest activity point and the point where activity fades, thus indicating the surgical resection margins. Once the tumour has been removed, handheld scanning of the surgical area will confirm that activity is only located within the tumoral specimen and that there is no residual activity requiring further excision.

Intraoperative probes are capable of detecting a very low flow of gamma photons. The sensitive part is at the end of a cylindrical tube of 1 to $2 \mathrm{~cm}$ in diameter. To ensure sterility, the tube is slipped into a long sleeve sterile flexible plastic disposable. It is connected by cable to an electronic unit which analyzes the signal, displays the count rate and beeps modulated by the level of radioactivity detected. The detection of gamma photons is ensured either by absorption in a scintillating crystal type sodium iodide or cesium iodide activated with thallium ( $\mathrm{NaI}(\mathrm{Tl})$ or $\mathrm{CsI}(\mathrm{Tl}))$ or in a semiconductor-type cadmium-tellurium ( Cd-Te) and cadmium-zinc-telluride (Cd-Zn-Te, sometimes abbreviated as CZT). In the first case, the signal emitted by the crystal must be amplified by a photomultiplier vacuum tube powered by a voltage of about 1000 volts, whereas with the semiconductor signal is 
processed immediately in low voltage and the system does not include a photomultiplier. However, detection volume identical stopping power and hence the detection sensitivity of sparkling crystals are higher than those of semiconductors.

The intraoperative detection probes currently available have a very high sensitivity to gamma photons emitted by technetium- $99 \mathrm{~m}$. They are also capable, with a setting often already pre-programmed to detect the emission of other isotopes commonly used in nuclear medicine (indium 111, iodine 131), even as the signal from the positron emitters such as 18fluoro- deoxyglucose (FDG). (Paredes et al, 2008)

Many studies showed that the use of a portable c-camera equipped for simultaneous $99 \mathrm{mTc}$ signal and Gd-153 pointer signal display can improve sentinel lymph node excision identification in breast carcinoma, prostate cancer, melanoma and other cutaneous malignancies.

Furthermore some authors adfirm that intraoperative realtime imaging by a c-camera can be used as an additional technique, besides preoperative lymphoscintigraphy, preoperative SPECT / CT and the intraoperative application of a hand-held c-probe (Cho et al 2009).

\section{Radioguided localization after neo-adjuvant chemotherapy}

The use of neo-adjuvant chemotherapy has increased in the treatment of loco-regionally advanced primarily operable breast cancer. As a result of improved neo-adjuvant chemotherapy regimens the number of clinical as well as radiological responses have increased. In case of a complete response it is difficult to identify residual disease and to perform an adequate radical breast-conserving surgery. Therefore localization of the original tumour bed is mandatory. The (125)I has a half-time of 60 days and is therefore still recognisable with a gamma probe after admittance of several courses of neo-adjuvant chemotherapy. (125)I seed localization is a highly successful technique in localizing the tumour bed in patients who receive neo-adjuvant chemotherapy for breast cancer leading to a high percentage of radical margins in case of breast-conserving surgery. (Straver et al, 2010a, 2010b; van Riet et al, 2010)

Nontheless an important benefit of neoadjuvant chemotherapy is the increased potential for breast-conserving surgery. At present also the response of axillary lymph node metastases to chemotherapy is not easily assessed, rendering axilla-conserving treatment difficult.

The tumour response in the marked lymph node may be used to tailor further axillary treatment, making axilla-conserving surgery a possibility. Moreover the high accuracy in visualizing lymph node metastases and the sufficiently high SUV(max) and tumour to background ratio at baseline suggest that it is feasible to monitor the axillary response with FDG PET/CT, especially in triple-negative tumours. (Choi et al, 2010)

\section{Conclusion}

Screening mammography is allowing detection of early breast cancer in an increasing number of women with occult, locally invasive or in situ carcinoma. The result is a marked decrease in the mean size of lesions, an increase in the incidence of in situ carcinomas and a reduction in axillary node involvement. Nuclear medicine techniques can help surgeons to identify both the tumor and the sentinel lymph nodes in order to stage the disease. 


\section{References}

Armer J, Fu MR, Wainstock JM, Zagar E K \& Jacobs LK. (2004). Lympheedema following breast cancer treatment, including sentinel lymph node biopsy. Lymphology; 37:73-91.

Armer JM, Stewart BR \& Shook RP. (2009). 30-Month post-breast cancer treatment lymphoedema. J Lymphoedema; 4:14-8

Ashikaga T, Krag DN, Land SR, Julian TB, Anderson SJ, Brown AM, Skelly JM, Harlow SP, Weaver DL, Mamounas EP, Costantino JP \& Wolmark N; National Surgical Adjuvant Breast, Bowel Project. (2010). Morbidity results from the NSABP B-32 trial comparing sentinel lymph node dissection versus axillary dissection. J Surg Oncol; 102:111-8.

Association of Breast Surgery. (2009). Surgical guidelines for the management of breast cancer. Eur J Surg Oncol; 35(Suppl. 1):1-22.

Barros A, Cardoso MA, Sheng PY, Costa PA \& Pelizon C. (2002). Radioguided localisation of non-palpable breast lesions and simultaneous sentinel lymph node mapping. Eur J Nucl Med Mol Imaging. 29(12):1561-5.

Barthelmes L, Goyal A, Newcombe RG, McNeill F \& Mansel RE. (2010). Adverse reactions to patent blue $V$ dye - The NEW START and ALMANAC experience. Eur J Surg Oncol, 36. 4: pp. 399-403.

Belloni E, Canevari C, Panizza P, Marassi A, Rodighiero M, Tacchini S, Zuber V, Sassi I, Gianolli L, Fazio F \& Del Maschio A. (2011). Nonpalpable breast lesions: preoperative radiological guidance in radioguided occult lesion localisation (ROLL). Radiol Med. 2011 Mar 7. [Epub ahead of print]

Boolbol SK, Fey JV, Borgen PI, Heerdt AS, Montgomery LL, Paglia M, Petrek JA, Cody HS $3^{\text {rd }} \&$ Van Zee KJ. (2001). Intradermal isotope injection : a highly accurate method of lymphatic mapping in breast carcinoma. Ann Surg Oncol; 8 : 3-6.

Celliers L \& Mann GB. (2003). Alternative sites of injection for sentinel lymph node biopsy in breast cancer. ANZ J Surg; 73(8):600-4.

Chen C, Chan MC, Hung WK, Lam HS \& Yip AW. (2005). Wire-guided excision of mammographic abnormalities. Hong Kong Med J; 11:153-7.

Cho N, Moon WK, Han W, Park IA, Cho J \& Noh DY. (2009). Preoperative sonographic classification of axillary lymph nodes in patients with breast cancer: node-to-node correlation with surgical histology and sentinel node biopsy results. Am J Roentgenol; 193: 1731-1737.

Choi JH, Lim HI, Lee SK, Kim WW, Kim SM, Cho E, Ko EY, Han BK, Park YH, Ahn JS, Im YH, Lee JE, Yang JH \& Nam SJ. (2010). The role of PET CT to evaluate the response to neoadjuvant chemotherapy in advanced breast cancer: comparison with ultrasonography and magnetic resonance imaging. J Surg Oncol; 102(5):392-7.

Chu TY, Lui CY, Hung WK, Kei SK, Choi CL \& Lam HS. (2010). Localisation of occult breast lesion: a comparative analysis of hookwire and radioguided procedures. Hong Kong Med J. 16(5):367-72.

Cody HS 3rd, Fey J, Akhurst T, Fazzari M, Mazumdar M, Yeung H, Yeh SD \& Borgen PI. (2001). Complementarity of blue dye and isotope in sentinel node localization for breast cancer : univariate and multivariate analysis in 966 procedures. Ann Surg Oncol; 8 : 13-9.

Cody HS \& Borgen PI. (1999). State-of-the-art approaches to sentinel node biopsy for breast cancer : study design, patient selection, technique and quality control at Memorial Sloan-Kettering Cancer Center. Surg Oncol; $8: 85-91$.

Crane-Okada R, Wascher RA, Elashoff D \& Giuliano AE. (2005). Longterm morbidity of sentinel node biopsy versus complete axillary dissection for unilateral breast cancer. Ann Surg Oncol; 15:1996-2005. 
Cremonesi M, Ferrari M, Sacco E, Rossi A, De Cicco C, Leonardi L, Chinol M, Luini A, Galimberti V, Tosi G, Veronesi U \& Paganelli G. (1999). Radiation protection in radioguided surgery of breast cancer. Nucl Med Commun. 20 (10):919-24)

Dayes IS. (2006). Current issues in the management of lymphedema in breast cancer patients. J Support Oncol. 4(8):392-3

Dayes IS, Levine MN, Julian JA, Pritchard KI, D'Souza DP, Kligman L, Reise D, Wiernikowski JA, Bonilla L \& Whelan TJ. (2008). Lymphedema in women with breast cancer: characteristics of patients screened for a randomized trial. Breast Cancer Res Treat; 110:337-42.

De Cicco C, Pizzamiglio M, Trifirò G, Luini A, Ferrari M, Prisco G, Galimberti V, Cassano E, Viale G, Intra M, Veronesi P \& Paganelli G. (2002). Radioguided occult lesion localization (ROLL) and surgical biopsy in breast cancer. Technical aspects. Q J Nucl Med.46(2):145-51.

De Cicco C, Trifirò G, Intra M, Marotta G, Ciprian A, Frasson A, Prisco G, Luini A, Viale G \& Paganelli G. (2004). Optimised nuclear medicine method for tumour marking and sentinel node detection in occult primary breast lesions. Eur J Nucl Med Mol Imaging.31(3):349-54.

Del Bianco P, Zavagno G, Burelli P, Scalco G, Barutta L, Carraro P, Pietrarota P, Meneghini G, Morbin T, Tacchetti G, Pecoraro P, Belardinelli V \& De Salvo GL. (2008). Morbidity comparison of sentinel lymph node biopsy versus conventional axillary lymph node dissection for breast cancer patients: results of the sentinella-GIVOM Italian randomised clinical trial. Eur J Surg Oncol; 34:508-13.

Derossis AM, Fey J, Yeung H, Yeh SD, Heerdt AS, Petrek J, VanZee KJ, Montgomery LL, Borgen PI \& Cody HS 3rd. (2001). A trend analysis of the relative value of blue dye and isotope localization in 2,000 consecutive cases of sentinel node biopsy for breast cancer. J Am Coll Surg; 193(5): 473-8.

Feggi L, Basaglia E, Corcione S, Querzoli P, Soliani G, Ascanelli S, Prandini N, Bergossi L \& Carcoforo P. (2001). An original approach in the diagnosis of early breast cancer: use of the same radiopharmaceutical for both non-palpable lesions and sentinel node localisation. Eur J Nucl Med. 28(11):1589-96

Gill G. (2009). Sentinel-lymph-node-based management or routine axillary clearance? One-year outcomes of sentinel node biopsy versus axillary clearance (SNAC): a randomized controlled surgical trial. Ann Surg Oncol; 16(2):266-75.

Giuliano AE, Kirgan DM, Guenther JM \& Morton DL. (1994). Lymphatic mapping and sentinel lymphadenectomy for breast cancer. Ann Surg; 220(3):391-8. discussion 398-401.

Gray RJ, Giuliano R, Dauway EL, Cox CE \& Reintgen DS. (2001). Radioguidance for nonpalpable primary lesions and sentinel lymph node(s). Am J Surg. 182(4):404-6.

Helyer LK, Varnic M, Le LW, Leong W \& McCready D. (2009). Obesity is a risk factor for developing postoperative lymphedema in breast cancer patients. Breast J.; 16:48-54.

Henze E, Schelbert HR, Collins JD, Najafi A, Barrio JR \& Bennett LR. (1982). Lymphoscintigraphy with Tc-99m-labeled dextran. J Nucl Med. 23(10):923-9.

Hunting AS, Nopp A, Johansson SG, Andersen F, Wilhelmsen V \& Guttormsen AB. (2010). Anaphylaxis to patent blue V. I. Clinical aspects. Allergy; 65(1):117-23.

Jakub JW, Gray RJ, Degnim AC, Boughey JC, Gardner M \& Cox CE. (2010). Current status of radioactive seed for localization of non palpable breast lesions. Am J Surg; 199(4):522-8.

Krag D, Weaver D, Ashikaga T, Moffat F, Klimberg VS, Shriver C, Feldman S, Kusminsky R, Gadd M, Kuhn J, Harlow S \& Beitsch P. (1998). The sentinel node in breast cancer: $a$ multicenter validation study. N Engl J Med;339(14):941-6. 
Kwan ML, Darbinian J, Schmitz KH, Citron R, Partee P, Kutner SE \& Kushi LH. (2010). Risk factors for lymphedema in a prospective breast cancer survivorship study: the Pathways Study. Arch Surg; 145:1055-63.

Leidenius M, Leivonen M, Vironen J \& von Smitten K.(2005). The consequences of long-time arm morbidity in node-negative breast cancer patients with sentinel node biopsy or axillary clearance. J Surg Oncol; 92:23-31.

Langer I, Guller U, Berclaz G, Koechli OR, Schaer G, Fehr MK, Hess T, Oertli D, Bronz L, Schnarwyler B, Wight E, Uehlinger U, Infanger E, Burger D \& Zuber M. (2007). Morbidity of sentinel lymph node biopsy (SLN) alone versus SLN and completion axillary lymph node dissection after breast cancer surgery: a prospective Swiss multicenter study on 659 patients. Ann Surg; 245: 452-61.

Leong SP, Donegan E, Heffernon W \& Dean S, Katz JA. (2000). Adverse reactions to isosulfan blue during selective sentinel lymph node dissection in melanoma. Ann Surg Oncol; 7 : 361-6.

Lucci A, McCall LM, Beitsch PD, Whitworth PW, Reintgen DS, Blumencranz PW, Leitch AM, Saha S, Hunt KK \& Giuliano AE. (2007). Surgical complications associated with sentinel lymph node dissection (SLND) plus axillary lymph node dissection compared with SLND alone in the American College of Surgeons Oncology Group Trial Z0011. J Clin Oncol.; 25:3657-63.

Luini A, Zurrida S, Galimberti V, Paganelli G. (1998). Radioguided surgery of occult breast lesions. Eur J Cancer; 34: 204- 5

Lyman GH, Giuliano AE, Somerfield MR, Benson AB 3rd, Bodurka DC, Burstein HJ, Cochran AJ, Cody HS 3rd, Edge SB, Galper S, Hayman JA, Kim TY, Perkins CL, Podoloff DA, Sivasubramaniam VH, Turner RR, Wahl R, Weaver DL, Wolff AC \& Winer EP. (2005). American Society of Clinical Oncology guideline recommendations for sentinel lymph node biopsy in early-stage breast cancer. J Clin Oncol; 23(30):7703-20.

Mansel RE, Fallowfield L, Kissin M, Goyal A, Newcombe RG, Dixon JM, Yiangou C, Horgan K, Bundred N, Monypenny I, England D, Sibbering M, Abdullah TI, Barr L, Chetty U, Sinnett DH, Fleissig A, Clarke D \& Ell PJ. (2006). Randomized multicenter trial of sentinel node biopsy versus standard axillary treatment in operable breast cancer: the ALMANAC Trial. J Natl Cancer Inst 98(9):599-609.

McLaughlin SA, Wright MJ, Morris KT, Giron GL, Sampson MR, Brockway JP, Hurley KE, Riedel ER \& Van Zee KJ. (2008). Prevalence of lymphedema in women with breast cancer 5 years after sentinel lymph node biopsy or axillary dissection: objective measurements. J Clin Oncol; 26:5213-9.

McLaughlin SA, Wright MJ, Morris KT, Sampson MR, Brockway JP, Hurley KE, Riedel ER \& Van Zee KJ. (2008). Prevalence of lymphedema in women with breast cancer 5 years after sentinel lymph node biopsy or axillary dissection: patient perceptions and precautionary behaviors. J Clin Oncol; 26:5220-6.

McMasters KM, Wong SL, Martin II RCG, Chao C, Tuttle TM, Noyes RD, Carlson DJ, Laidley AL, McGlothin TQ, Ley PB, Brown CM, Glaser RL, Pennington RE, Turk PS, Simpson D, Cerrito PB \& Edwards MJ. (2001). Dermal injection of radioactive colloid is superior to peritumoral injection for breast cancer sentinel lymph node biopsy: results of a multiinstitutional study. Ann Surg; 233 : 676-87.

Nieweg OE, Estourgie SH, van Rijk MC \& Kroon BB. (2004). Rationale for superficial injection techniques in lymphatic mapping in breast cancer patients. J Surg Oncol; 87(4):153-6.

Noguchi M. (2004). Current controversies concerning sentinel lymph node biopsy for breast cancer. Breast Cancer Res Treat.; 84(3):261-71. 
Paredes P, Vidal-Sicart S, Zanón G, Roé N, Rubí S, Lafuente S, Pavía J \& Pons F. (2008). Radioguided occult lesion localisation in breast cancer using an intraoperative portable gamma camera: first results. Eur J Nucl Med Mol Imaging; 35(2):230-5.

Patel A, Pain SJ, Britton P, Sinnatamby R, Warren R, Bobrow L, Barber RW, Peters AM \& Purushotham AD. (2004). Radioguided occult lesion localisation (ROLL) and sentinel node biopsy for impalpable invasive breast cancer. Eur J Surg Oncol.30(9):918-23.

Perry NM. (2001). EUSOMA Working Party. Quality assurance in the diagnosis of breast disease. EUSOMA Working Party. Eur J Cancer; 37:159-72.

Querci della Rovere G, Ahmad I, Singh P, Ashley S, Daniels IR \& Mortimer P. (2003). An audit of the incidence of arm lymphoedema after prophylactic level I/II axillary dissection without division of the pectoralis minor muscle. Ann R Coll Surg Engl; 85:158-61.

Rampaul RS, Dudley NJ, Thompson JZ, Burrell H, Evans AJ, Wilson AR \& Macmillan RD. (2003). Radioisotope for occult lesion localisation (ROLL) of the breast does not require extra radiation protection procedures. Breast. 12(2):150-2

Schrenk P, Rieger R, Shamiyeh A \& Wayand W. (2000). Morbidity following sentinel lymph node biopsy versus axillary lymph node dissection for patients with breast carcinoma. Cancer; 88: 608-14.

Somasundaram SK, Chicken DW \& Keshtgar MR. (2007). Detection of the sentinel lymph node in breast cancer. Br Med Bull; 84:117-31.

Straver ME, Aukema TS, Olmos RA, Rutgers EJ, Gilhuijs KG, Schot ME, Vogel WV \& Peeters MJ. (2010). Feasibility of FDG PET/CT to monitor the response of axillary lymph node metastases to neoadjuvant chemotherapy in breast cancer patients. Eur J Nucl Med Mol Imaging; 37(6):1069-76.

Straver ME, Loo CE, Alderliesten T, Rutgers EJ \& Vrancken Peeters MT. (2010). Marking the axilla with radioactive iodine seeds (MARI procedure) may reduce the need for axillary dissection after neoadjuvant chemotherapy for breast cancer. Br J Surg; 97(8):1226-31.

Strnad P, Rob L, Halaska MG, Chod J, Zuntova A \& Moravcova Z. (2006) Radioguided occult lesion localisation in combination with detection of the sentinel lymph node in non-palpable breast cancer tumours.Eur J Gynaecol Oncol.27(3):236-8.

Tafra L, Lannin DR, Swanson MS, Van Eyk JJ, Verbanac KM, Chua AN, Ng PC, Edwards MS, Halliday BE, Henry CA, Sommers LM, Carman CM, Molin MR, Yurko JE, Perry RR, Williams R. (2001). Multicenter trial of sentinel node biopsy for breast cancer using both technetium sulfur colloid and isosulfan blue dye. Ann Surg; 233(1):51-9.

van der Ploeg IM, Hobbelink M, van den Bosch MA, Mali WP, Borel Rinkes IH \& van Hillegersberg R. (2008). 'Radioguided occult lesion localisation' (ROLL) for non-palpable breast lesions: a review of the relevant literature. Eur J Surg Oncol. 34(1):1-5.

van Riet YE, Maaskant AJ, Creemers GJ, van Warmerdam LJ, Jansen FH, van de Velde CJ, Rutten HJ \& Nieuwenhuijzen GA. (2010). Identification of residual breast tumour localization after neo-adjuvant chemotherapy using a radioactive 125Iodine seed. Eur J Surg Oncol; 36(2):164-9.

Veronesi U, Paganelli G, Viale G, Luini A, Zurrida S, Galimberti V, Intra M, Veronesi P, Robertson C, Maisonneuve P, Renne G, De Cicco C, De Lucia F \& Gennari R.. (2003). A randomized comparison of sentinel-node biopsy with routine axillary dissection in breast cancer. N Engl J Med.; 349:546-53.

White V, Harvey JR, Griffith CDM, Youssef M \& Carr M. (2011). Sentinel lymph node biopsy in early breast cancer surgery: Working with the risks of vital blue dye to reap the benefits. EJSO 37 101-108 


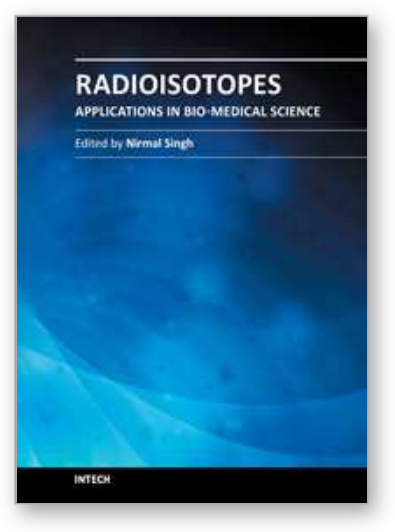

\author{
Radioisotopes - Applications in Bio-Medical Science \\ Edited by Prof. Nirmal Singh
}

ISBN 978-953-307-748-2

Hard cover, 320 pages

Publisher InTech

Published online 21, November, 2011

Published in print edition November, 2011

The book Radioisotopes - Applications in Bio-Medical Science contains two sections: Radioisotopes and Radiations in Bioscience and Radioisotopes and Radiology in Medical Science. Section I includes chapters on medical radioisotope production, radio-labeled nano-particles, radioisotopes and nano-medicine, use of radiations in insects, drug research, medical radioisotopes and use of radioisotopes in interdisciplinary fields etc. In Section II, chapters related to production of metal PET (positron emission tomography) radioisotopes, 3-dimensional and CT (computed tomography) scan, SS nuclear medicine in imaging, cancer diagnose and treatments have been included. The subject matter will by highly useful to the medical and paramedical staff in hospitals, as well as researchers and scholars in the field of nuclear medicine medical physics and nuclear biochemistry etc.

\title{
How to reference
}

In order to correctly reference this scholarly work, feel free to copy and paste the following:

Luciano Izzo, Sara Savelli, Andrea Stagnitti and Mario Marini (2011). Nuclear Medicine in the Imaging and Management of Breast Cancer, Radioisotopes - Applications in Bio-Medical Science, Prof. Nirmal Singh (Ed.), ISBN: 978-953-307-748-2, InTech, Available from: http://www.intechopen.com/books/radioisotopesapplications-in-bio-medical-science/nuclear-medicine-in-the-imaging-and-management-of-breast-cancer

\section{INTECH}

open science | open minds

\author{
InTech Europe \\ University Campus STeP Ri \\ Slavka Krautzeka 83/A \\ 51000 Rijeka, Croatia \\ Phone: +385 (51) 770447 \\ Fax: +385 (51) 686166 \\ www.intechopen.com
}

\author{
InTech China \\ Unit 405, Office Block, Hotel Equatorial Shanghai \\ No.65, Yan An Road (West), Shanghai, 200040, China \\ 中国上海市延安西路65号上海国际贵都大饭店办公楼405单元 \\ Phone: +86-21-62489820 \\ Fax: +86-21-62489821
}


(C) 2011 The Author(s). Licensee IntechOpen. This is an open access article distributed under the terms of the Creative Commons Attribution 3.0 License, which permits unrestricted use, distribution, and reproduction in any medium, provided the original work is properly cited. 